\title{
Detection Probability and Occupancy of American Woodcock during Singing-ground Surveys
}

STEFANIE M. BERGH, ${ }^{1,2}$ Minnesota Cooperative Fish and Wildlife Research Unit, University of Minnesota, St. Paul, MN 55108 , USA

DAVID E. ANDERSEN, U.S. Geological Survey, Minnesota Cooperative Fish and Wildlife Research Unit, University of Minnesota, St. Paul, MN 55108, USA

\begin{abstract}
The Singing-ground Survey (SGS) was designed to exploit the conspicuous breeding-season display of male American woodcock (Scolopax minor; hereafter, woodcock) to monitor these otherwise inconspicuous birds. The SGS was standardized in 1968 and has since been conducted annually to derive an index of abundance and population trend. Counts of singing male woodcock on the SGS have generally declined through time, but without knowledge of the relationship among counts, woodcock abundance, and the factors affecting detection, considerable uncertainty remains in interpretation of SGS data. Using modified SGS protocols, we surveyed SGS routes in Pine County, Minnesota, in 2009 and 2010 and developed models to assess factors associated with detection probability and estimated occupancy. The intercept-only model (i.e., constant detection and occupancy probabilities across sites and no covariates) included overall detection probability of $0.59(\mathrm{SE}=0.018)$ in 2009 and $0.66(\mathrm{SE}=0.017)$ in 2010 with an occupancy estimate of 0.74 (SE $=0.049)$ in 2009 and $0.81(\mathrm{SE}=0.044)$ in 2010. The best-supported model of detection probability for both years combined included detection as a function of woodcock abundance, observer, date, disturbance level (i.e., ambient noise that interfered with detecting woodcock), and wind speed. High wind speeds were negatively related to detection, different observers had different detection probabilities, date was quadratically related to detection (indicating a mid-period peak in detection), and high woodcock abundance and low disturbance levels were positively related to detection. We provide suggestions for incorporating these resulting into SGS protocol and analyses.
\end{abstract}

Proceedings of the American Woodcock Symposium 11: 20o-208

KEY WORDS: American woodcock, detection probability, Minnesota, occupancy, Scolopax minor

The American woodcock (Scolopax minor; hereafter, woodcock) is a migratory game bird that occurs in forested landscapes in eastern and central North America. During the spring, male woodcock perform distinctive courtship behavior in a variety of openings (e.g., natural openings, clearcuts, agricultural fields) called singing grounds. Woodcock are pursued as game birds in southern Canadian provinces from Manitoba eastward, and throughout the central, eastern, and southeastern United States (U.S.); they are migratory and are managed federally under auspices of the Migratory Bird Treaty Act in the U.S. and the Migratory Birds Convention Act in Canada. Woodcock populations are monitored via the North American Woodcock Singing-ground Survey (SGS), coordinated by the U. S. Fish and Wildlife Service (FWS) and the Canadian Wildlife Service. This survey has been conducted throughout primary woodcock breeding range since 1968 , with results used as an index of abundance and to estimate population trends (Seamans and Rau 2016). From 1968 to 2016, the numbers of singing male woodcock counted on SGS routes declined 0.93\% per year in the Eastern Region (southern Quebec, the maritime Canadian provinces, and the northeast and mid-Atlantic U.S., east of the Appalachian Divide) and 0.68\% per year in the Central Management Region (south-

1 email: Stefanie.Bergh@dfw.wa.gov

2 current address: Washington Department of Fish and Wildlife, P.O. Box 484,

White Salmon, WA 98672, USA

$\overline{\text { https://doi.org/10.24926/AWS.0126 }}$ CC BY 4.0 
ern Ontario and the Midwestern U.S. south to the Ohio River Valley; Seamans and Rau 2016). Concerns about declines in the number of woodcock detected on the SGS have led to harvest restrictions (summarized in Seamans and Rau 2016), development of a woodcock conservation plan (Kelley et al. 2008), and a need to better understand how counts of woodcock on the SGS are related to woodcock abundance and population trends.

As with most indices of abundance, the SGS is based on an assumed relationship between counts and abundance that is not well documented (Anderson 2001). One important and untested assumption underlying the SGS is that all male breeding woodcock occupying a listening point are heard peenting (the vocalization made by displaying male woodcock) on the night of the survey, or that a constant proportion of males present are detected among years (Thogmartin et al. 2007). However, the relationship between number of woodcock heard on surveys and number of woodcock present is unknown (e.g., Kozicky et al. 1954). Furthermore, a number of factors can influence detection probability of displaying male woodcock during the SGS, including weather, observer ability, woodcock behavior, woodcock density, ambient noise levels, land cover surrounding SGS listening points, and distance from and orientation of a peenting woodcock relative to the listening point. How these factors influence SGS counts is not well documented.

The SGS was designed to minimize the influence of environmental factors on woodcock counts by prescribing conditions under which a survey is conducted, and optimizing conditions that influence whether male woodcock display and whether displaying woodcock are detected (e.g., Goudy 1960, Duke 1966). The SGS protocol precludes surveys during heavy precipitation, strong $(>19.3 \mathrm{~km} / \mathrm{hr} ; 12 \mathrm{mph})$ wind, or temperatures below $4.4^{\circ}$ $\mathrm{C}\left(40^{\circ} \mathrm{F}\right)$. However, weather conditions may still affect detection of woodcock on the SGS. Simons et al. (2007) found that the proportion of breeding songbirds heard under breezy $(10-25 \mathrm{~km} / \mathrm{hr})$ conditions decreased by $28 \%$ compared to calm conditions. Furthermore, ambient noise level ("disturbance"), which includes traffic noise and other human-caused or natural (e.g., frogs, other birds) sounds, can affect the ability of observers to detect woodcock. Simons et al. (2007) reported that proportion of birds detected decreased by $41 \%$ in the presence of other singing birds ( $1-3$ singing birds) and $42 \%$ with addition of $10 \mathrm{~dB}$ of white noise. Ambient noise level is not taken into account in SGS analyses by the FWS.

Ability to detect woodcock likely varies among observers and may change through time, although observer ability is not directly assessed in SGS analyses. Duke (1966) recommended hearing tests for observers, specifically for the frequency range of woodcock peenting. Simons et al. (2007) recognized that age-related hearing loss combined with and compounded by a general increase in ambient noise in occupied habitats through time has the potential to decrease detection probabilities of birds. Current analyses of SGS counts incorporate the observer-route combination and first year for observers (Sauer et al. 2008), but the magnitude of variation among observers is unknown.

Presence and behavior of neighboring woodcock could also affect likelihood of or rate that woodcock display, which in turn could influence woodcock counts during the SGS. For example, Duke (1966) found that in some instances peenting rates were greater during a 2-min listening period when woodcock were alone compared to when they were close to 1 or 2 other woodcock. McAuley et al. (1993) noted that dominant males peented consistently throughout the evening, whereas subdominant males remained quiet or peented intermittently. Similarly, Godfrey (1974) reported that subdominant males moved to various singing grounds during the evening display period and peented intermittently near the dominant male of that singing ground. It is not clear how presence of other woodcock influences displaying birds, or how this might influence SGS counts, and the influence of other woodcock on detection probability has not been assessed.

To address how environmental, observer, and conspecific factors influenced detection probability of male woodcock during the SGS, we quantified effects of these factors on detection probability of woodcock under the conditions of the SGS in east-central Minnesota, USA. Because the primary goal of monitoring woodcock is to estimate abundance and population trends, we also estimated detection-corrected occupancy of woodcock on SGS routes. Incorporating detection probability to estimate woodcock occupancy may provide an alternative approach to assessing trends in woodcock abundance, potentially improving interpretation of SGS counts.

\section{Study Area}

We conducted our study in Pine County, Minnesota, USA during the springs of 2009 and 2010. Pine County is located in east-central Minnesota $\left(\sim 92^{\circ} 17.5^{\prime}-93^{\circ} 8.5^{\prime} \mathrm{W}\right.$ and $\left.45^{\circ} 43.3^{\prime}-46^{\circ} 24.7^{\prime} \mathrm{N}\right)$ and is characterized by drumlin ridges with depressions between the ridges containing peatlands with shallow organic material, and extensive wetlands. During the period of our study, large areas in eastern Pine County were heavily forested, dominated by aspen-birch (Populus spp.-Betula spp.) forest with small areas of pine (Pinus spp.) forests. Land use was dominated by $40 \%$ forest, followed by $24 \%$ row crop, $17 \%$ wetland-open, $13 \%$ pasture, and $6 \%$ water (Minnesota DNR 2006). Mean maximum temperatures by month during our study ranged from $11.6^{\circ} \mathrm{C}$ to $19.6^{\circ} \mathrm{C}$ and mean minimum temperatures ranged from $-1.4^{\circ} \mathrm{C}$ to $5.3^{\circ} \mathrm{C}$ (Minnesota Climatology Working Group 2010). 


\section{Methods}

\section{DATA COLLECTION}

In April and May we surveyed the 4 established SGS routes in Pine County (routes 77, 80, 86, and 91), and 4 additional randomly located routes (included to increase sample size) following the official SGS protocol for conducting surveys, except that we initiated surveys earlier than the period prescribed by the SGS protocol (see below). Locations of established SGS routes were determined by the FWS (see Seamans and Rau 2016) and consisted of 10 listening points evenly distributed along $5.4 \mathrm{~km}$ of secondary road. We visited the starting point of each route and digitized route locations using a Geographic Information System (ArcMap 9.3; use of trade names does not imply endorsement by either the U.S. Government or the University of Minnesota). We located reference routes randomly by selecting a Universal Transverse Mercator coordinate within Pine County using Hawth's Analysis Tools (Hawth's Analysis Tools for ArcGIS Version 3.27, www.spatialecology.com/htools, accessed 10 February 2009) then locating, using a randomly selected cardinal direction (Microsoft Office Excel 2003), the nearest secondary road.

Five ( 2 in 2009, 2 in 2010, and 1 in both 2009 and 2010) different observers conducted surveys on both SGS and reference routes. Observers had their hearing evaluated and we trained them to listen for woodcock by conducting surveys along the established SGS routes in Pine County before the start of the sampling period. We surveyed each of the 8 routes (10 points per route) once on each of 4 days during 3 of the 6 weeks during the breeding-season study period, resulting in 80 points surveyed 12 times over the course of the survey period. We also recorded the cardinal direction and estimated distance to each woodcock we detected on each survey to identify woodcock displaying at approximately the same location among surveys during the same year, and treated woodcock detected displaying at the same location as individuals in our analyses of covariates associated with detection (see below). Based on this experimental design, we made the assumption of a closed population (i.e., no changes in occupancy) and assessed trends in detection throughout the spring. It took 2 weeks to survey all 8 routes, starting with the southernmost routes and progressing north. The 6-week survey periods were 12 April - 21 May 2009 and 10 April - 19 May 2010. We initiated surveys earlier than the SGS protocol-recommended 25 April because we needed a longer period than the $<6$-week period prescribed by the SGS protocol to survey each route 12 times. We also wanted to allow for the possibility that woodcock may return earlier to breeding areas than they have in the past to account for potential effects of climate change on the timing of spring behavior of birds (e.g., Murphy-Klassen et al. 2005, Jonzén et al. 2006).

We recorded temperature, wind speed, sky condition, precipitation, and disturbance level (see below) for each survey in the same manner as the official SGS protocol. Disturbance level described the ambient noise at each listening point in 1 of 4 categories: none, low, moderate, and high. Because these categories are subjective, we grouped them into quiet (none or low) and noisy (moderate or high; e.g., Kissling et al. 2010). The official SGS protocol includes 5 categories of precipitation: none, mist, snow or heavy rain, fog, and light rain. Because fog never occurred during surveys over the course of our 2-year study period and mist only occurred 4 times, we grouped fog and mist with light rain to indicate presence of light precipitation. This study was conducted under protocol 0801A24506 approved by the Institutional Animal Care and Use Committee at the University of Minnesota.

\section{DATA ANALYSIS}

We estimated occupancy $(\psi)$ and detection probability $(p)$ of male woodcock based on the detection history from repeated surveys at each listening point along routes using the approach of MacKenzie et al. (2002, 2006). The repeated surveys assess occupancy in a population assumed to be closed [i.e., an individual woodcock remains associated with its singing ground(s) throughout the survey period and displaying male woodcock do not immigrate into the study area during the survey period]. This method uses a closed-population model to estimate occupancy rates when detection probabilities are $<1$ and allows for the inclusion of covariate information via a logistic model. A detection history of ones (detection) and zeroes (no detection) at $N$ sites over $T$ visits is recorded along with all covariate data associated with each listening point.

We used program PRESENCE (PRESENCE2-Software to estimate patch occupancy and related parameters, mbrpwrc.usgs.gov/software/presence.html, accessed 2 June 2009) to estimate detection probability and occupancy across survey points for survey data from 2009, 2010, and 2009-2010 combined. We also used PRESENCE to assess whether occupancy changed within years across the sampling period as an evaluation of whether we met our assumption of population closure, by estimating occupancy for each third of the survey period (mid-April, lateApril through early May, and mid-May).

PRESENCE estimates both occupancy and detection probability in a hierarchical model. Therefore, to preclude confounding factors associated with both detection probability and occupancy, we use repeated measures logistic regression (R Version 2.11.1, www.r-project.org, accessed 29 June 2010) to identify factors (e.g., wind speed, observer, date; Table 1) associated with detection probability of individual woodcock (woodcock detected at the same location among surveys, see above). The probability that we detected an individual male woodcock as a function of the measured covariates was: 


$$
\operatorname{logit}(p)=\beta_{\mathrm{o}}+\beta_{1} x_{\mathrm{i1}}+\beta_{2} x_{i 2}+\cdots,+\beta_{U} x_{i U}
$$

We examined factors related to detection probability in a sequential model-selection approach (Burnham and Anderson 2002), where we first evaluated single-covariate models, and then added multi-covariate models based on Akaike's Information Criterion (AIC; Akaike 1973), similar in concept to the approaches used by Yates and Muzika (2006), Amundson and Arnold (2010), and Daly et al. (2015). We considered 7 single-covariate models [neighbor, wind, temperature, precipitation, observer, date, quiet], the global model (all covariates), and the intercept-only (null) model for 2009, 2010, and 2009-2010 combined. We included Julian date as a quadratic covariate to account for a peak in singing activity by males during the breeding season (Goudy 1960, Sheldon 1967). We included year as a covariate when combining data from both years to indicate surveys conducted in 2009 or 2010.

We ranked single-covariate models using AIC and used the single-covariate model with the lowest AIC value as the base model for considering additional covariates. We

Table 1. Covariates considered in assessing factors related to detection and occupancy of American woodcock on Singing-ground Surveys in Pine County, Minnesota, 2009-2010.

\begin{tabular}{ll}
\hline Variable & Description \\
\hline Year & Indicates 2009 or 2010 survey. \\
& $\begin{array}{l}\text { Indicates which of } 5 \text { observers } \\
\text { conducted a survey over the 2-year } \\
\text { study period. }\end{array}$ \\
Wind & $\begin{array}{l}\text { Wind speed at the time of the survey. } \\
\text { Categorical variable per SGS guidelines. }\end{array}$ \\
Date & $\begin{array}{l}\text { Julian date. Included a quadratic term to } \\
\text { represent a peak in detections. }\end{array}$ \\
Temperature & $\begin{array}{l}\text { Temperature at the start of the survey. } \\
\text { Four categories: } 2-3.9^{\circ} \mathrm{C}, 4-9.5^{\circ} \mathrm{C}, \\
\text { 9.6-15 }{ }^{\circ} \mathrm{C},>15.1^{\circ} \mathrm{C} .\end{array}$ \\
Precipitation & $\begin{array}{l}\text { Presence or absence of any type of light } \\
\text { precipitation (rain, mist, fog) during } \\
\text { the survey. }\end{array}$ \\
Neighbor & $\begin{array}{l}\text { Presence and detection of } \geq 2 \text { displaying } \\
\text { woodcock at a listening point. }\end{array}$ \\
Quiet & $\begin{array}{l}\text { Ambient noise level at each listening } \\
\text { point as in official SGS protocol } \\
(4 \text { categories: none, low, moderate, }\end{array}$ \\
& $\begin{array}{l}\text { high). An indicator variable for none or } \\
\text { low ambient noise with null indicating } \\
\text { moderate or high ambient noise. }\end{array}$ \\
\hline
\end{tabular}

sequentially added covariates to this base model, in the order of support of covariates based on AIC values, until adding a covariate did not reduce the AIC value of the multi-covariate model by $\geq 2$ (e.g., Yates and Muzika 2006, Popescu and Gibbs 2009, Kissling et al. 2010). We then used AIC to identify the models in the set of single-covariate models, the global model, the null model, and the subset of multi-covariate models best supported by our data and to calculate AIC model weights ( $w_{i}$; Burnham and Anderson 2002). We considered competing models to be the model best supported by the data (i.e., having the lowest AIC value) and models within 2 AIC units $(\triangle \mathrm{AIC} \leq 2)$ of that model that also improve model fit (as measured by a decrease in model deviance if they include additional covariates, Arnold 2010). We also evaluated 10,000 bootstrap samples of global models to test for overdispersion of the data, which is indicated by a variance inflation factor $(\hat{c})>1.0$ (Burnham and Anderson 2002). We used the variance inflation factor to modify AIC by:

$$
Q A I C=-[2 \log -\text { likelihood } / \hat{\mathrm{c}}]+2 K \text {. }
$$

We compared occupancy and detection probability estimates between years and among categories based on $95 \%$ confidence intervals and assessed relative importance of model covariates by summing model weights across all candidate models (Burnham and Anderson 2002) that included each covariate. We evaluated evidence for statistical significance based on whether $95 \%$ confidence intervals around parameter estimates contained zero, and report model-averaged parameter estimates (Burnham and Anderson 2002) for covariates associated with detection probability. Finally, we compared detection frequency of individual woodcock across surveys using a chi-squared test (Microsoft Office Excel 2003) to evaluate whether there was evidence of differences in woodcock association with individual singing grounds between years.

\section{Results}

In 2009, we conducted surveys on each of our 8 routes $(n=$ 80 listening points) 12 times, and identified 125 individual woodcock (based on cardinal direction and estimated distance from a listening point) at 59 (74\%) listening points. In 2010, we also conducted surveys on each of our 8 routes ( $n=80$ listening points) 12 times, and identified 177 individual woodcock at $65(81 \%)$ listening points. The proportion of surveys in which we detected individual woodcock within a year ranged from approximately 0.08 ( 1 survey; approximately $20 \%$ of individual woodcock) to 1.0 ( 12 surveys; also approximately $20 \%$ of individual woodcock). The distribution of the proportion of surveys in which we detected an individual woodcock was similar between years $\left(\chi_{9}^{2}=3.68, P=0931\right)$, suggesting that individ- 
ual woodcock used multiple singing grounds (McAuley et al. 1993) similarly between years.

\section{DETECTION PROBABILITY}

The intercept-only model with detection and occupancy probabilities constant across listening points and survey routes $[\psi(),. p()$.$] derived using PRESENCE had an over-$ all detection probability of $0.59(\mathrm{SE}=0.018)$ in 2009 and $0.66(\mathrm{SE}=0.017)$ in 2010 . The $95 \%$ confidence intervals for these 2 years did not overlap: $(0.56,0.63)$ and $(0.63,0.70)$ for 2009 and 2010, respectively, suggesting that detection probability across survey points was slightly lower in 2009 than in 2010.
The best-supported single-covariate model of detection probability (based on repeated measures logistic regression) for 2009 included neighbor and ranked below the global model ( $\triangle \mathrm{AIC}=6.3$; Table 2$)$. In 2010, the best-supported single-covariate model of detection probability included neighbor, and also ranked below the global model $(\triangle \mathrm{AIC}=7.7$; Table 2). Similarly, when we combined data from 2009 and 2010, the best-supported single-covariate model of detection probability included neighbor, which ranked considerably below the global model $(\triangle \mathrm{AIC}$ = 23.6; Table 2).

After considering addition of covariates to the best-supported single-covariate model, the best-supported model of detection probability for 2009 included the covari-

Table 2. Covariates in models of detection probability of individual male American woodcock, Akaike's Information Criterion (AIC), difference of AIC between a model and the model with the lowest AIC $(\triangle \mathrm{AIC})$, model weights $\left(w_{\mathrm{i}}\right)$, number of parameters in the model $(K)$, and model deviance (Dev) for the 6 candidate models we used to evaluate factors related to detection of individual American woodcock on Singing-ground Surveys in Pine County, Minnesota, for 2009, 2010, and 2009-2010 combined.

\begin{tabular}{|c|c|c|c|c|c|}
\hline Model & $\mathrm{AIC}_{\mathrm{c}}$ & $\Delta \mathrm{AIC}_{\mathrm{c}}$ & $\omega_{i}$ & $K$ & Dev \\
\hline \multicolumn{6}{|l|}{2009} \\
\hline Neighbor + Observer + Quiet + Wind & 1783.4 & 0.0 & 0.792 & 6 & 1771.4 \\
\hline Neighbor + Observer + Quiet + Wind + Date $^{a}$ & $1787 \cdot 3$ & 3.9 & 0.113 & 8 & 1771.3 \\
\hline Neighbor + Observer + Quiet & 1788.3 & 4.9 & 0.068 & 5 & 1778.3 \\
\hline Global & 1790.4 & 7.0 & 0.024 & 10 & 1770.4 \\
\hline Neighbor + Observer & 1794.8 & 11.4 & 0.003 & 4 & 1786.8 \\
\hline Neighbor & 1796.7 & $13 \cdot 3$ & 0.000 & 2 & 1792.7 \\
\hline Null & 2139.4 & 356.0 & 0.000 & 1 & 2137.4 \\
\hline \multicolumn{6}{|l|}{2010} \\
\hline Neighbor + Date + Quiet + Observer & 1973.6 & 0.0 & 0.448 & 7 & 2351.3 \\
\hline Neighbor + Date + Quiet + Observer + Precip ${ }^{a}$ & 1974.8 & 1.2 & 0.245 & 8 & 2350.5 \\
\hline Neighbor + Date + Quiet & 1975.3 & 1.7 & 0.191 & 5 & 2360.7 \\
\hline Neighbor + Date & $1977 \cdot 3$ & 3.7 & 0.070 & 4 & 2363.1 \\
\hline Global & 1978.3 & 4.6 & 0.045 & 10 & 2349.9 \\
\hline Neighbor & 1986.0 & 12.4 & 0.001 & 2 & 2378.4 \\
\hline Null & 2450.5 & 476.8 & 0.000 & 1 & 2448.5 \\
\hline \multicolumn{6}{|l|}{ 2009-2010 } \\
\hline Global & 4153.7 & 0.0 & 0.349 & 13 & 4127.7 \\
\hline Neighbor + Quiet + Observer + Wind + Date & 4154.2 & 0.5 & 0.272 & 10 & 4134.2 \\
\hline Neighbor + Quiet + Observer + Wind + Date + Precip & $4154 \cdot 5$ & 0.8 & 0.234 & 11 & 4132.5 \\
\hline Neighbor + Quiet + Observer + Wind & 4155.8 & 2.1 & 0.122 & 8 & 4139.8 \\
\hline Neighbor + Quiet + Observer & 4159.1 & 5.4 & 0.023 & 7 & 4145.1 \\
\hline Neighbor + Quiet & 4167.6 & 13.9 & 0.000 & 3 & 4161.6 \\
\hline Neighbor & $4177 \cdot 3$ & 23.6 & 0.000 & 2 & $4173 \cdot 3$ \\
\hline Null & $5077 \cdot 4$ & 923.7 & 0.000 & 1 & 5075.4 \\
\hline
\end{tabular}


ates neighbor, observer, quiet, and wind, and received 7 times more Akaike model weight (AIC $w_{\mathrm{i}}$ ) than the second-ranked model. Wind was negatively related to detection probability, one observer had higher detection probability than the other 2 (although 95\% CIs overlapped), and neighbor and quiet were positively related to detection probability. The cumulative model weights for individual covariates across candidate models were neighbor $=1.0$, observer $=1.0$, quiet $=0.997$, wind $=0.929$, date $=0.137$, temperature $=0.024$, and precipitation $=0.024$ (Table 2). The best-supported multi-covariate model of detection probability for 2010 included the covariates neighbor, date, quiet, and observer. Akaike model weight for the best-supported model was 2 times greater than for the second-ranked model. As in 2009, one observer had a higher detection probability than the other 2 observers (although 95\% CIs overlapped), date had a quadratic relationship with detection probability, and neighbor and quiet were positively related to detection probability. The cumulative model weights for individual covariates were neighbor $=1.0$, date $=0.999$, quiet $=0.929$, observer $=0.738$, precipitation $=$ 0.290 , wind $=0.045$, and temperature $=0.045$ (Table 2).

The best-supported model of detection probability for 2009 and 2010 combined was the global model, which had a lower deviance and a higher number of parameters than the rest of the candidate models. Wind was negatively related to detection probability, Observer 1 had a higher detection probability than the other 4 observers (although 95\% CIs overlapped), date had a quadratic relationship with detection probability (Fig. 1), and neighbor and quiet were positively related to detection probability (Table 3 ). The 95\% confidence interval around the parameter estimates ( $\beta$ i's) contained zero for year, precipitation, and temperature, suggesting these covariates did not have a strong relationship with detection probability, even though they appeared in the best-supported model. The cumulative model weights for individual covariates were neighbor $=1.0$, quiet $=1.0$, observer $=1.0$, wind $=$ 0.977 , date $=0.855$, precipitation $=0.583$, and temperature $=0.339$ (Table 2). Bootstrap simulations for 2009 and 2009-2010 combined provided no evidence of overdispersion in the data ( $\hat{c}=0.33,0.43$, respectively) whereas 2010 showed slight overdispersion $(\hat{c}=1.2)$.

\section{OCCUPANCY}

Based on the intercept-only model with constant detection and occupancy probabilities and no covariates $[\psi(),. p()$.$] ,$ we estimated woodcock occupancy across survey points at $0.74(\mathrm{SE}=0.049)$ in 2009 and $0.81(\mathrm{SE}=0.044)$ in 2010. Occupancy appeared to increase (although 95\% CIs overlapped across the sampling period) through our sampling period in 2009, but not in 2010 (Fig. 1). The point estimate of occupancy in 2009 was lower than in 2010 for the earlyand mid-spring periods, but similar between years during the late-spring period (Fig. 2), although 95\% CIs overlapped among periods within years, indicating no strong indication of a peak in occupancy.

\section{Discussion}

We estimated detection probability and occupancy of male woodcock at survey points along 4 SGS routes and 4 routes patterned after SGS routes in east-central Minnesota, and documented relatively high occupancy in both 2009 and 2010. Thogmartin et al. (2007) identified east-central Minnesota as an area of high woodcock abundance, based on their landscape-scale models. Our observations of high occupancy (0.74 in 2009 and 0.81 in 2010) also suggest high woodcock abundance in this landscape.

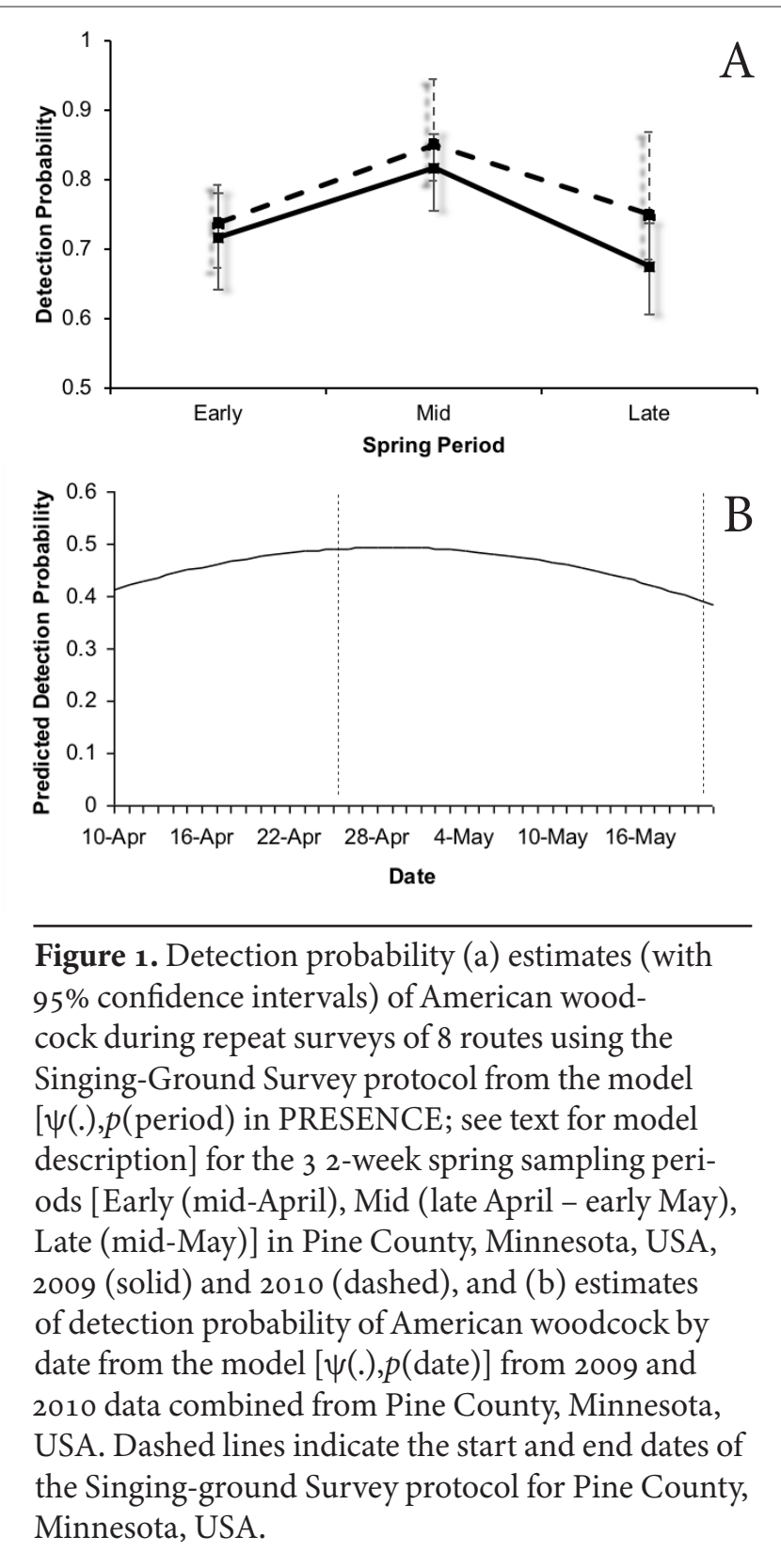


We observed differences between years in estimated occupancy, which may be a consequence of the dynamic nature of use of singing grounds among years by woodcock as described by Godfrey (1974) and McAuley et al. (1993), or of real change in abundance of woodcock between years.

The detection probabilities we estimated were lower (0.59 in 2009 and 0.66 in 2010) than perfect detection ( $p$ $=1.0$ ), suggesting that accounting for factors influencing detection in standardized surveys with single visits to individual listening points could improve estimation of occupancy and description of trends in woodcock abundance. We identified 4 factors that were related to detection probability of woodcock using the SGS protocol; neighbor, observer, date, and quiet. Neighbor, which indicated the presence of $>1$ woodcock singing at an SGS listening point during a survey, had a strong positive relationship with detection, perhaps due to social facilitation (i.e., motivation to call in the presence of a conspecific) and the competitive nature of male woodcock during the breeding season (Sheldon 1967). Our study area in east-central Minnesota had a higher estimated abundance of woodcock than many other areas (Thogmartin et al. 2007), so whether presence of a conspecific would be related to detection at lower woodcock density is unknown. If calling by one woodcock elicits peenting from neighboring woodcock, call broadcasts could increase detection probability, potentially most effectively at low woodcock abundance.

Table 3. Model-averaged parameter estimates $(\beta)$ and $95 \%$ confidence interval limits for detection probability covariates included in the global model of factors related to detection probability of individual American woodcock in Pine County, Minnesota, 2009-2010.

\begin{tabular}{|c|c|c|c|}
\hline Variable & $\beta$ & $\begin{array}{c}95 \% \text { lower } \\
\text { CL }\end{array}$ & $\begin{array}{c}95 \% \text { upper } \\
\text { CL }\end{array}$ \\
\hline $\begin{array}{l}\text { Intercept/ } \\
\text { Observer5 }\end{array}$ & -1.72 & -2.42 & -1.03 \\
\hline Date & 0.022 & -0.007 & 0.050 \\
\hline Date $^{2}$ & $<-0.000$ & -0.001 & $<-0.000$ \\
\hline Observer 1 & 0.049 & -0.202 & 0.299 \\
\hline Observer2 & -0.241 & -0.625 & 0.143 \\
\hline Observer3 & -0.116 & -0.497 & 0.265 \\
\hline Observer4 & -0.288 & -0.534 & -0.042 \\
\hline Precipitation & -0.123 & -0.494 & 0.241 \\
\hline Wind & -0.044 & -0.082 & -0.006 \\
\hline Temperature & 0.009 & -0.003 & 0.021 \\
\hline Quiet & 0.283 & 0.122 & 0.445 \\
\hline Neighbor & 2.11 & 1.96 & 2.26 \\
\hline Year & 0.112 & -0.160 & 0.385 \\
\hline
\end{tabular}

Our models also indicated an observer effect, although approximately half the time the $95 \%$ confidence interval for these coefficients contained zero. Even though observers in our study were tested for hearing and possessed the ability to hear woodcock peenting (unlike the SGS, where observers are not screened for auditory acuity), we still documented observer effects. It is probably not feasible to assess the ability of SGS observers to detect peenting woodcock, in part because many cooperators are volunteers, but differential ability of observers to detect woodcock likely adds considerable random variation, and approaches to control this variation may be warranted.

Our results also suggested the presence of a peak in detection probability during the spring, as evidenced by the inclusion of a quadratic date covariate in the best-supported models of detection probability. A mid-spring peak in detection was also evident when we plotted detection probability through time (Fig. 1), and likely can be explained by a peak in displaying by male woodcock (Goudy 1960, Sheldon 1967). If surveys were timed to be close to this peak, detection probability would likely be higher than if surveys were conducted earlier or later in the season. However, this peak was included within the official survey window for Pine County and it may not be logistically feasible to conduct surveys in a shorter window of time than identified in the current SGS protocol.

Quiet, which indicated that the ambient noise level was "none" or "low" at a listening point during a survey, also had a positive association with detection probability compared to surveys conducted during periods with higher ambient noise levels (i.e., "noisy"), although not as strong as did "neighbor." This covariate may have been con-

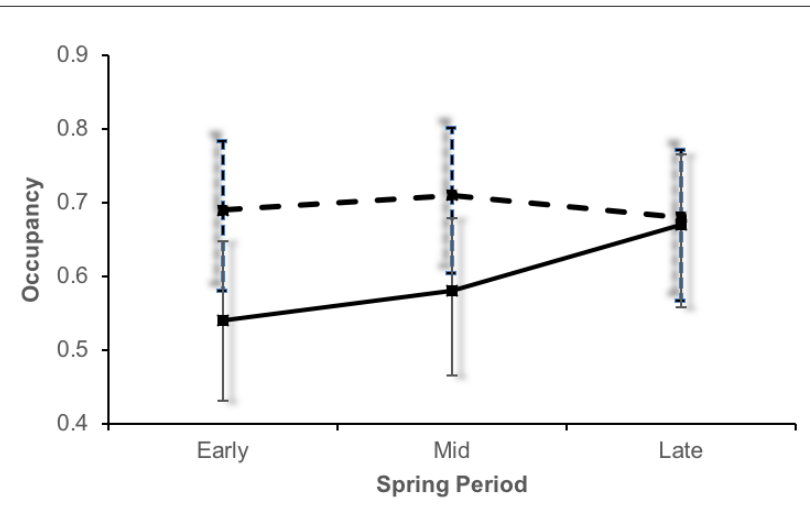

Figure 2. American woodcock occupancy estimates (with 95\% confidence intervals) across listening points from the model $[\psi($ period $), p()$.$] for the 3$ 2-week spring sampling periods [Early (mid-April), Mid (late April - early May), Late (mid-May)] in Pine County, Minnesota, USA, 2009 (solid) and 2010 (dashed). 
founded with precipitation because light rain, especially when leafout has occurred, can temporarily increase ambient noise during part or all of a survey. Also, on busier secondary roads where ambient noise level can be quite variable, accounting for this relationship would likely improve the accuracy of estimating short-term population trends as traffic noise during surveys likely varies among years.

We also note that detection probability in both 2009 and 2010 was similar even though we employed different observers and conducted surveys under variable spring weather conditions, which suggests that detection probability may be relatively constant among years, at least over the conditions we encountered. If this is the case, then at least at smaller spatial scales (e.g., the scale of our study), detection probability may be relatively constant through time. However, at larger spatial scales (e.g., the scale of states or Management Regions), whether there is spatial variation in detection probability is not known.

Finally, whether our assumption of population closure during our 3-week survey period was met is not clear. In Maine, individual male woodcock moved among singing grounds during the spring (McAuley et al. 1993), and similar movement by individual males among signing grounds in our study could have influenced our results in 2 ways. First, if movement by individual males resulted in singing grounds being unoccupied during some surveys, our occupancy estimates may be biased low, especially if such movement occurred disproportionately at sites where only 1 woodcock was present. In our study, the distribution of the proportion of surveys when we detected individual woodcock (identified as woodcock displaying at individual locations) was similar between years, suggesting that movement among singing grounds by individual males was also similar between years. Under that circumstance, our occupancy estimates between years are directly comparable, although they may be biased low for both years. Second, if our assessment of covariates associated with detection probability of individual woodcock included multiple individuals identified as the same individual at a particular singing ground, variation among those individuals may have resulted in lower power to detect associations. In that case, the strength of the associations we identified may have been under-estimated. Finally, at a broader spatial scale, some male woodcock may be present along survey routes for only a portion of the SGS window (Moore et al., this volume). The magnitude and extent of such movements is not well documented, although in our study, the potential influence of such movements would be similar to the influence of smaller-scale movements, described above.

\section{Management Implications}

We suggest that, to better document and understand the influence of factors related to detection at a larger spatial scale than we were able to assess in our study, a subset of
SGS routes at various locations throughout the woodcock breeding range could be surveyed repeatedly and environmental factors measured to assess their association with detection probability. This could lead to quantifiable guidelines on when to conduct surveys and what factors are most important to consider when interpreting data resulting from the SGS.

First, for each latitudinal region, the survey window could be evaluated and possibly condensed to ensure that surveys are being completed during the peak display period. Second, observer variation in the SGS is likely at least as large as in our study, and training and testing observers would likely reduce this variation. Third, routes could be evaluated to determine if the road(s) being used has experienced increases in traffic levels since the routes were established in 1968. SGS routes with unsafe road conditions can be replaced through official protocol, and an assessment of continued inclusion of routes with high vehicle traffic or other sources of noise seems warranted. Finally, detection probability of woodcock on SGS routes decreases in precipitation stronger than a mist, likely due to a decrease in the observer's ability to hear woodcock over the noise of the precipitation. Data resulting from surveys of routes on the SGS during such conditions likely under-represent woodcock abundance and we suggest that they should be discarded.

\section{Acknowledgments}

D. Prokop and the Finlayson-Giese Sportsmen's Club provided housing and support during field work. We are grateful for the hard work of field technicians J. A. Fritz, B. J. Oberschmid, N. R. Bieber, and J. C. Bietka. Helpful advice and comments were provided by T. R. Cooper, R. J. Gutiérrez, and D. H. Johnson. Statistical advice and help with program $\mathrm{R}$ were provided by the Statistics Department at the University of Minnesota. J. R. Kelley assisted in generating support for this project from the U.S. Fish and Wildlife Service and H. Saloka provided administrative and logistical support for field work at the U.S. Geological Survey Minnesota Cooperative Fish and Wildlife Research Unit (MNCFWRU). This project was funded by the U.S. Fish and Wildlife Service Webless Migratory Game Bird Research Program through Research Work Order no. 81 at the MNCFWRU.

\section{Literature Cited}

Akaike, H. 1973. Information theory and an extension of the maximum likelihood principle. Pages 267-281 in B.N. Petrov and F. Csaki, editors. Second International Symposium on Information Theory. Akademiai Kiado, Budapest, Hungary.

Amundson, C.L., and T.W. Arnold. 2010. Effects of radiotransmitters and placticine bands on mallard duckling survival. Journal of Field Ornithology 81:310-316.

Anderson, D.R. 2001. The need to get the basics right in wildlife field studies. Wildlife Society Bulletin 29:1294-1297. 
Arnold, T.W. 2010. Uninformative parameters and model selection using Akaike's Information Criterion. Journal of Wildlife Management 74:1175-1178.

Burnham, K.P. and D.R. Anderson. 2002. Model selection and inference: a practical information-theoretic approach. Spring-Verlag, New York, USA.

Daly, K.O., D.E. Andersen, W.L. Brininger, and T.R. Cooper. 2015. Radio-transmitters have no impact on survival of pre-fledged American woodcocks. Journal of Field Ornithology 86:345-351.

Duke, G.E. 1966. Reliability of censuses of singing male woodcock. Journal of Wildlife Management 30:697-707.

Godfrey, G.A. 1974. Behavior and ecology of American woodcock on the breeding range in Minnesota. Dissertation. University of Minnesota, St. Paul, Minnesota, USA.

Goudy, W.H. 1960. Factors affecting woodcock spring population indexes in southern Michigan.M.S. Thesis. Michigan State University, East Lansing, Michigan, USA.

Jonzén N., A. Lindén, T. Ergon, E. Knudsen, J.O. Vik, D. Rubolini D. Piacentini, C. Brinch, F. Spina, L. Karlsson, M. Stervander, A. Andersson, J. Waldenström, A. Lehikoinen, E. Edvardsen, R. Solvang, N.C. Stenseth. 2006. Rapid advance of spring arrival dates in long-distance migratory birds. Science 312:1959-1961.

Kelley, J.R., S.J. Williamson, and T.R. Cooper, editors. 2008. American woodcock conservation plan: a summary of and recommendations for woodcock conservation in North America. Wildlife Management Institute, Washington D.C., USA.

Kissling, M.L., S.B. Lewis, G. Pendelton. 2010. Factors influencing the detectability of forest owls in southeastern Alaska. Condor 112:539-548.

Kozicky, E.L., T.A. Bancroft, and P.G. Homeyer. 1954. An analysis of woodcock singing ground counts, 1948-1952. Journal of Wildlife Management 18:259-266.

MacKenzie, D.I., J.D. Nichols, G.B. Lachman, S. Droege, J.A. Royle, and C.A. Langtimm. 2002. Estimating site occupancy rates when detection probabilities are less than one. Ecology 83: 2248-2255.

MacKenzie, D.I., J.D. Nichols, J.A. Royle, K.H. Pollock, L.L. Bailey, and J.E. Hines. 2006. Occupancy estimation and modeling: inferring patterns and dynamics of species occurrence. Elsevier, Burlington, Massachusetts, USA.

McAuley, D.G., J.R. Longcore, and G.F. Sepik. 1993. Behavior of radio-marked breeding American woodcocks. Pages 116-125 in J.R. Longcore and G.F. Sepik, editors. Proceedings of the Eighth
American Woodcock Symposium. U.S. Fish and Wildlife Service, Biological Report 16. Washington, D.C., USA.

Minnesota Climatology Working Group. 2010. Historical Climate Data Retrieval. <http://climate.umn.edu/doc/historical.htm>. Accessed 28 Jan 2011.

Minnesota Department of Natural Resources. 2006. Tomorrow's habitat for the wild and rare: an action plan for Minnesota wildlife. Comprehensive Wildlife Conservation Strategy. Division of Ecological Services, Minnesota Department of Natural Resources. St. Paul, Minnesota, USA.

Moore, J.D., T.R. Cooper, R. Rau, D.E. Andersen, J. P. Duguay, C.A. Stewart, and D.G. Krementz. 2019. Assessment of the American woodcock singing-ground survey zone timing and coverage. Pages 181-192 in D.G. Krementz, D.E. Andersen, and T. R. Cooper, Editors. Proceedings of the Eleventh American Woodcock Symposium. University of Minnesota Libraries Publishing, Minneapolis, Minnesota, USA.

Murphy-Klassen H.M.T.J. Underwood, S.G. Sealy, A.A. Czyrnyj. 2005. Long-term trends in spring arrival dates of migrant birds at Delta Marsh, Manitoba, in relation to climate change. Auk 122:1130-1148.

Popescu, V.D and J.P. Gibbs. 2009. Interactions between climate, beaver activity, and pond occupancy by the cold-adapted mink frog in New York State, USA. Biological Conservation 142:2059-2068.

Sauer, J.R., W.A. Link, W.L. Kendall, J.R. Kelley and D.K. Niven. 2008. A hierarchical model for estimating change in American woodcock populations. Journal of Wildlife Management 72:204-214.

Seamans, M.E., and R.D. Rau. 2016. American woodcock population status, 2016. U.S. Fish and Wildlife Service, Laurel, Maryland.

Sheldon, W.G. 1967. The book of the American woodcock. University of Massachusetts Press, Amherst, Massachusetts, USA.

Simons, T.R., M.W. Alldredge, K.H. Pollock, and J.M Wettroth. 2007. Experimental analysis of the auditory detection process on avian point counts. Auk 124:986-999.

Thogmartin, W.E., J.R. Sauer, and M.G. Knutson. 2007. Modeling and mapping abundance of American woodcock across the midwestern and northeastern United States. Journal of Wildlife Management 71:376-382.

Yates, M.D. and R.M. Muzika. 2006. Effect of forest structure and fragmentation on site occupancy of bat species in Missouri Ozark forests. Journal of Wildlife Management 70:1238-1248. 